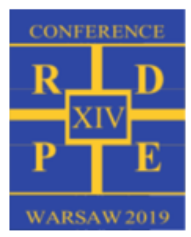

\title{
Reverse engineering methodology as a way of steam turbine blades designing for Loviisa Nuclear Power
}

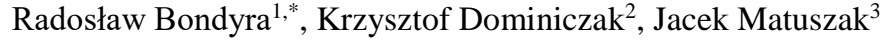 \\ ${ }^{1}$ GE Power LTD, ul. Stoczniowa 2, 82-300 Elbląg, Instytut Maszyn Przepływowych PAN, ul. Generała Stanisława Fiszera 14, 80-231 \\ Gdańsk, radoslaw.bondyra@ge.com, Poland \\ 2 GE Power LTD, ul. Stoczniowa 2, 82-300 Elblagg, Instytut Maszyn Przepływowych PAN, ul. Generała Stanisława Fiszera 14, 80-231 \\ Gdańsk, krzysztof.dominiczak@ge.com, Poland \\ ${ }^{3}$ GE Power LTD, ul. Stoczniowa 2, 82-300 Elbląg, jacek.matuszak@ge.com, Poland
}

\begin{abstract}
This article concerns a reverse engineering-based design process of last stage blade (LSB) for other original equipment manufacturer (OOEM). For Loviisa Power Plant (Finland) GE designed and delivered a set of $00 E M L S B s$ to be fit into existing low pressure (LP) turbine module steam path. Although cost competitiveness is a one of major selection criterion for steam turbine spare parts components supplier, diversification of suppliers is also a strategic for power plant owner. Considered here is a process of reengineering of $00 E M L S B$ and all relevant challenges related to this process especially management of geometry deviations between reverse-engineered and $00 \mathrm{EM}$ blade. In this article, there are a design steps described taken to qualify reverse-engineered design. Moreover, a manufacturing process of the LSB is shown.
\end{abstract}

\section{Introduction}

To meet constantly incising customer requirements, GE has launched a reverse engineering process to compete on OOEM market, which is a design and manufacturing process based on a projection of already existing object. Reverse engineering capabilities significantly increase a steam turbine manufacturer competitiveness and increase its product portfolio. This article describes one of the GE projects, which delivered a reversed-engineered LSB for LP module of OOEM nuclear steam turbine.

Described here reverse engineering capabilities, allowed GE Power to offer, design, manufacture and install OOEM LSB. However, the reverse engineering process is characterized by a high-risk level, which needs to be carefully managed. A main risk is related to a creation of a virtual 3D model of an object as well as the validation of newly designed elements based on it. Regardless all challenges, a risk management of reverse engineering process allowed to mitigate all potential risks on a level accepted by a nuclear safety and enabled a delivery of LSB to the Loviisa Nuclear Power Plant, located in Finland.

\section{Loviisa - Nuclear Power Plant}

Loviisa - a nuclear power plant, is located in Finland on the small Hästholmen peninsula, near the town of Loviisa, about $100 \mathrm{~km}$ from Helsinki. It produces $7.8 \mathrm{TWh}$ of electricity, which is more than $11 \%$ of the energy produced in Finland. In addition, it produces district heating energy. The power plant, which consists of two units, has been commissioned in 1977. Power generation is based on two Russian pressurized water reactors (PWR) with a rated power of $507 \mathrm{MW}$ per each. An interesting fact is that plant plants owns a training facility. There is a reactor installed which was purchased from Poland, where originally was supposed to be installed in Żarnowiec.

Each unit has a two 200MW class steam turbine installed. These units were modernized by OEM in late 90 's [1]. The turbine shaft line consists of a high-pressure part and two low-pressure parts made in impulse technology (Fig. 1). Currently, one unit (i.e. two turbines) is able to produce $522-524 \mathrm{MW}$ of electricity and about $1500 \mathrm{MW}$ of thermal energy.

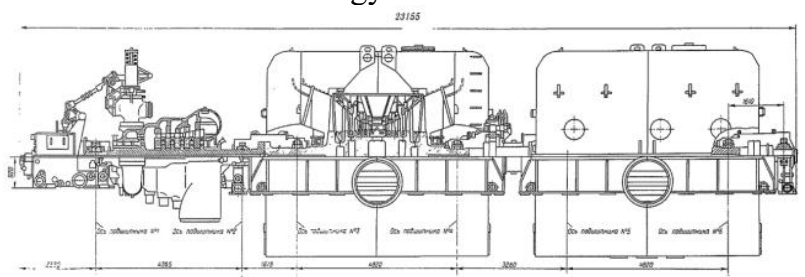

Fig. 1. Loviisa unit 1 steam turbine cross-section.

\section{OEM last stage blades}

Despite nearly 40 years of cooperation between the Loviisa power plant and OEM, in 2016 GE Power signed a contract for the supply of three sets of last stage blades for the low-pressure part of steam turbines installed in Loviisa. Power plant wanted to diversify a LSB supply source due to make LSB prices more competitive and ensure an alternative supply source to mitigate risks related to unstable political situation in oOEM country. 


\subsection{Design description}

All relevant to LSB data was obtain from reverse engineering process. For a purpose of the process based on contract agreement, GE was handed four OEM blades from the power plant warehouse. Two of them were used and two were new. Additionally, an on-site measurement campaign was conducted to capture a relevant rotor geometry i.e. interface between LP rotor and LSB. Figure 2 shows a sketch of the reverse-engineered last stage blade.

LSB has a shroud and one dumping wire located in vicinity of a mean diameter. The total blade length is $1103,5 \mathrm{~mm}$, whereas airfoil high is $1030 \mathrm{~mm}$. LSB root has fir-tree design. The material of OEM was identified as high alloyed steel.

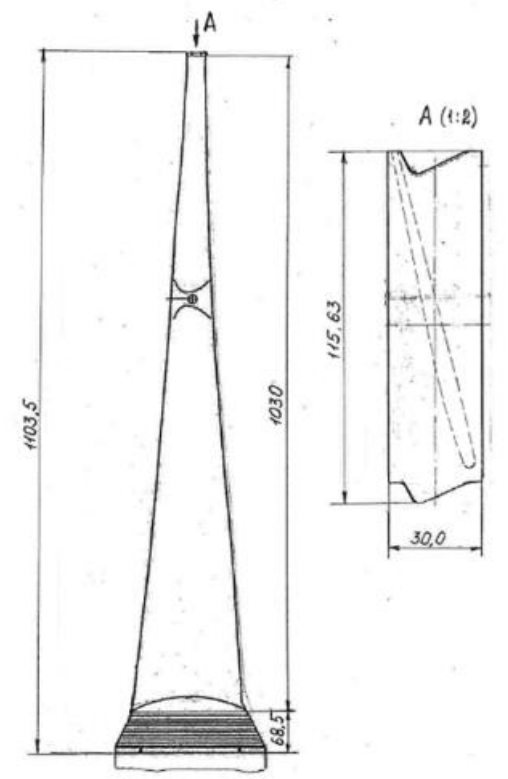

Fig. 2. D raft of the 5th stage blade of low-pressure steam turbine module.

\subsection{Requirements for LSB}

The main power plant owner requirement was to provide a blade which would not be geometrically different than oOEM LSB, which allow assembly on existing LP rotors. The plant owner required LSB strength characteristics at the similar level to oOEM design. Additionally, there was a requirement for LSB material Charpy impact test not to be lower than 50J. Moreover, reverse-engineered LSB was required to have similar dynamic characteristic than oOEM blade not to interfere with dynamic behaviour of the steam turbine. As a part of contractual obligation, GE delivered a few dummy blades, which allowed power plant verification of LSB geometry and feasibility of assembly process.

\subsection{Description of reverse engineering methodology}

The LSB was reconstructed only based on a physically existing element. For this purpose, a series of tests and measurements have been conducted to design LSB on required similarity level to oOEM design.

\subsubsection{Blade 3D model reconstruction method}

The reverse engineering process began with a selection of appropriate blades to be scanned with blue light scanner. The selection took placed in power plant storage, where 14 LSB (10 new and 4 used) were fully inspected by GE. The inspection revealed a poor quality of available for measurement LSBs, especially in leading and trailing edges, which were not straight (Fig. 3). The poor quality of available samples significantly hindered a reconstruction process. After further investigation and measurements, origins for reversed engineered LSB were selected and followed by detail scanning.

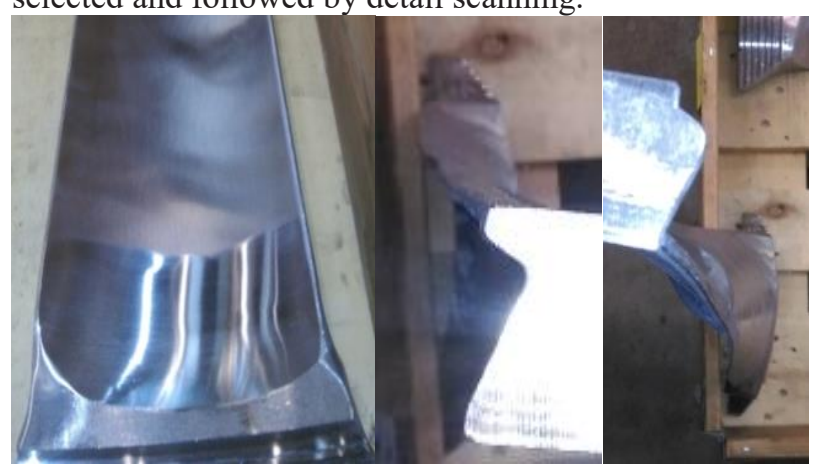

Fig. 3. Poor condition of a new 0 OEM LSB used for reverse engineering.

Due to the fact, that blades selected for scanning had significant geometrical discrepancies, each of the selected blades was scanned three times using blue light scanner. As a result, 18 points cloud models were obtained and next postprocessed to choose the most representative one. The state-of-the art engineering software were used for postprocessing where scanned points were appropriately corrected and LSB geometry verified. In the next stage of the reverse engineering process, LSB geometry model surfaces were created in engineering software from verified cloud points. In the next step model were imported to Catia V5, which was a target software to create $3 \mathrm{D}$ models and manufacturing documentation. As a result of the process, 18 3D models of LSB were obtained. The largest and smallest profiles were selected and compared (Fig. 4). The shape averaged in size finally served as nominal and values from extremes were treated as production deviations

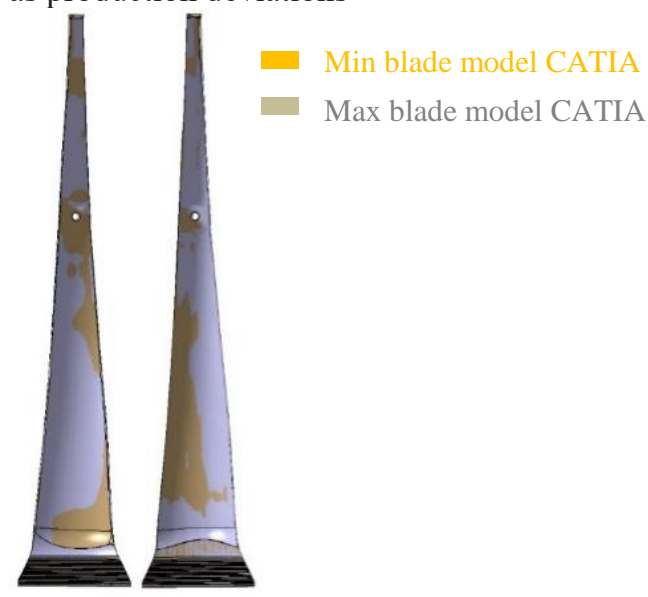

Fig. 4. Comparison of min, max models CATIA . 
An important aspect of steam turbine LSB design is its root fastening. In this particular case, it is an interface that must have been properly adapted to the existing LP rotor groove and oOEM LSB. To obtain rotor groove geometry and assembly tolerances, a similar approach was taken as for LSB. There was an onsite measurement campaign to capture this aspect of the reverse engineering process. After visual inspection, five grooves and related to them LSB from each flow were selected as representative. Further roots models were compared with groove models and their fitting was verified [Fig.5]. Some geometry corrections were required but in general this part of the reverse engineering process was ended successfully.
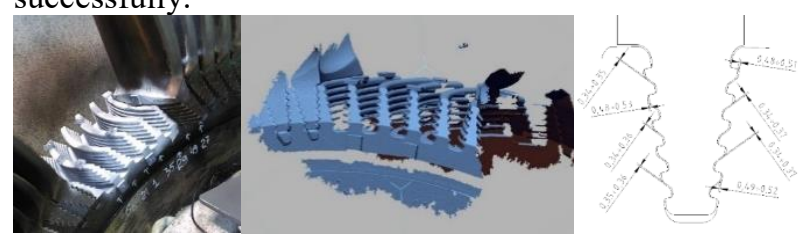

Fig. 5. The process of scanning the rotor grooves and verification by analysing the groove and root fit.

\subsubsection{Technical specification and manufacture technology of the last stage blade}

Parallel to the creation of $3 \mathrm{~d}$ models, other investigation relevant for LSB technical specification were carried out, i.e. selection of equivalent material, corrosion protection technology for the leading edge, etc. Based on available samples of oOEM LSB, a series of tests were conducted to determine a baseline for LSB acceptance criteria. For instance, to find the state-of-theart solution to protect the leading edge of LSB, GE Power conducted a following tests:

1. visual inspection

2. verification of the blade surface under the microscope

3. hardness test on leading edge \& shroud (HV5 \& HV1 method)

4. comparative chemical analysis of leading Edge

5. blade natural frequencies test stress calculations

Further in this section, these tests are described in detail.

All blades provided by the power plant were subjected to visual assessment (1). First, the test was carried out on new oOEM LSB. Surfaces without wear caused by operational factors, were used to determine requirements for a manufacturing technology. It was observed that the protection of the leading edge was made by spraying a special coating. The protected area covers a larger surface than required by GE Power design standards. The presence of this coating was also visible on the radius between the shroud and the airfoil.

LSB after 120000 operating hours of service life, were also been inspected to determine a weak points of oOEM to improve the design. In general, technical condition of used LSB was very good. However, erosion of the leading edge was observed over a section of about $300 \mathrm{~mm}$ in the upper part of the blade and on the transition radius of the shroud and airfoil. This clearly indicates a need for a larger protective coating zone.
The main purpose of the microscope examination (2) was to check whether the blade surface bears signs of shot peening. This kind of treatment is performed to increase the hardness of the treated surface. As a result of this test, no features of such a procedure were noticed, so the theory of the use of a special coating instead of shot peening was confirmed.

The next stage of investigation was hardness tests performed (3) on the leading edge of the airfoil and on a shroud. The HV5 and HV1 methods were applied and the Zwick3212 tool was used to perform them. The analysis has shown that coated zone has about $200 \mathrm{HV}$ better results than the parent material. The obtained results confirmed the presence of a special coating based on the difference in results for the surface of the airfoil (where visual inspection stand that coating appears) and the remaining part of the blade. Differences were about 200HV.

The last study was a comparative analysis of the chemical composition (4). The main purpose was to check what kind of coating was used to protect the leading edge in the original blades. Based on this test results, it was concluded that the most likely a sprayed titanium tungsten coating (cemented carbide) was used to protect oOEM LSB. Base on this investigation results, a leading-edge protection technology for new LSB was selected not to be worse than for oOEM LSB.

\subsection{Verification of the LSB manufacturing process}

Based on the requirements of the Loviisa Power Plant, GE Power manufactured and delivered on site dummy blades at the early stage of the project to allow amendments in the LSB design if required. Six dummy blades per flow were delivered to the power plant. The blades were made of high alloyed steel and were not subjected to any treatments as per final manufacturing process of reverse engineered blades

The main purpose of this procedure was to check the three main interfaces:

- $\quad$ fitting of the blade root to the rotor groove

- position of the damping wire hole

- blade shroud fit

As a result of the dummy blades assembly on site in a spare LP rotor, there were a few amendments to the LSB design. The design of the blade root and dumping wire were slightly adjusted. It was also spotted that the shape of the shroud corresponds to oOEM but there is a slight difference in shroud thickness. Additionally, the shape of leading and trailing edges of the aerofoil was not satisfactory and had to be corrected. However, the dummy blades trial installation was successful and GE gained an experience which allowed to adjust LSB design accordingly.

An important aspect of dummy blades installation was a verification of rotating row assembly procedure, especially assembly of the last blade in the row. Dummy blades installation proved that oOEM assembly and disassembly procedures are feasible for reverse engineered LSBs. This was an important project 
milestone, which gave a green light of manufacturing of 624 LSBs, which were a final deliverable of the project.

\section{Last stage blades strength \& dynamic assessment}

In order to prove that LSB design meets all contractual requirements as well as all internal GE design criteria, mechanical integrity and dynamic analysis were performed. The design was verified by means of:

- $\quad$ static and dynamic stress

- dynamic assessment

- fatigue assessment

All relevant analyses were made using finite element method in ABAQUS, which is a commercial FE software.

\subsection{Description of 3D model used for calculation}

For the sake of assessment, a geometry model was prepared, and appropriate boundary conditions were applied. 3D approach was used to accurately capture all relevant aspects of the design [3]. Analysis covers maximum and minimum aerofoil geometry to mitigate any risk related to accuracy of the reverse engineering. It was decided to proceed with maximum and minimum aerofoil geometry despite the small differences between both geometries. A dynamic behaviour of the LSB was a concern. However, analysis shown that differences between two considered models are insignificant but nuclear safety always go first.

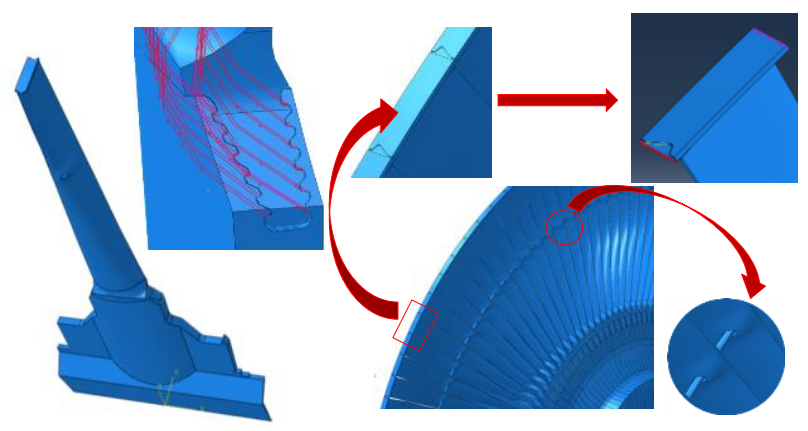

Fig. 6. 3D Geometry model for calculation purpose overview.

Figure 6 shows the model prepared for the analysis. Only one sector of the rotor circumference was modelled, which corresponded to one LSB. A cyclic symmetry was used in the model. Figure 6 also presents the contact between LSB root and LP rotor blade groove. Other interfaces are also visible, i.e. the interaction between shrouds of subsequent blades and the interface with the damping wire. This modelling strategy allowed to significantly reduce computation time but without influencing analysis accuracy. Next, discreet model was prepared based on quadratic hexahedron elements. Later, relevant loads were applied to the model.

\subsection{Strength analysis of reverse engineered LSB}

In order to verify the strength of the reverse engineered LSB according to GE Power design rules, stress in all relevant LSB feature were compared to permissible values. One of the major design criteria concerns stresses in the aerofoil. The maximum stress was observed in the transition radius between root and airfoil (Figure 7). Stresses in blade root, shroud as well as in the dumping wire have been checked. Based on a stress level in the LSB and based on positive service history, a good operation behaviour of the LSB was foreseen. Nevertheless, all stress related design criteria were met, and blade were qualified as per GE internal design criteria.

The leading-edge protection zone was also verified. This area of blade was described in section 3.3.2. The surface is located on the blade airfoil i.e. from the shroud up to damming wire. Based on stress field analysis, it was concluded that protection can be done by means of coating process.

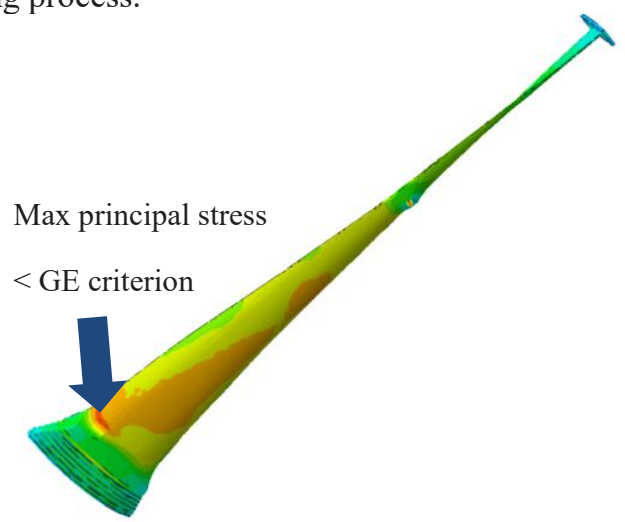

Fig. 7. Results of blade airfoil strength analysis.

\subsection{Dynamic assessment}

Natural vibration frequencies analysis was conducted to verify dynamic behaviour of the reverse engineered LSB. The analysis covers all relevant loads [4] related to LSB operation regime as well as loads for rotor unbalance.

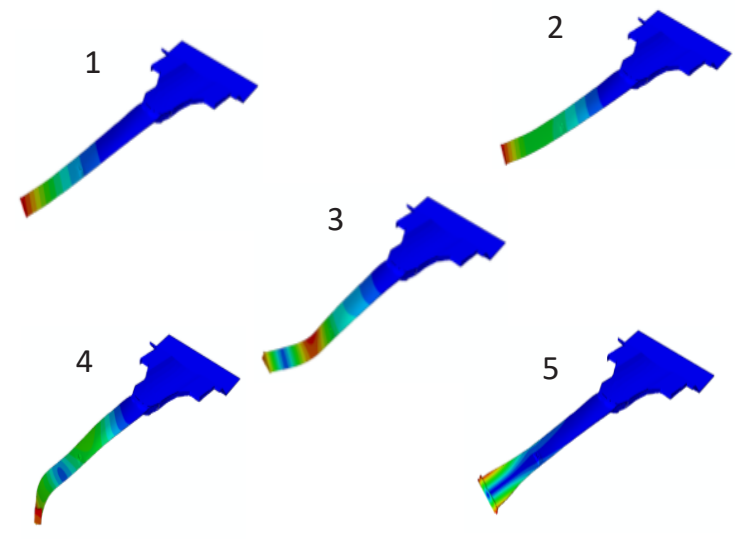

Fig. 8. V isualization of modes of frequencies.

One of the main customer requirements was to compare the frequencies of oOEM blade with reverse engineered one. Additionally, the GE Power project team decided to compare the calculated natural frequencies values for the maximum and the minimum airfoil geometry. This was to verify the impact of slight geometrical changes on a dynamic of LSB row. Table 1 shows the results for five modes of vibration at 0rpm. Figure 8 shows vibration modes of the LSB. Most of 
mode were bending or torsional-bending. Comparing the maximum and the minimum airfoil models, it can be seen, that the maximum deviation between frequencies values reaches $8.5 \%$ at 5 mode. Based on all results it was stated that differences had no significant impact on the dynamics of the entire LSB row. To fully compare both models an interference diagram was prepared (Figure 9). There are no discrepancies up to 7 nodal diameters for all relevant engine orders. There are slight differences between two models for higher nodal diameters. However, the deviation is small up to $4-5 \%$.

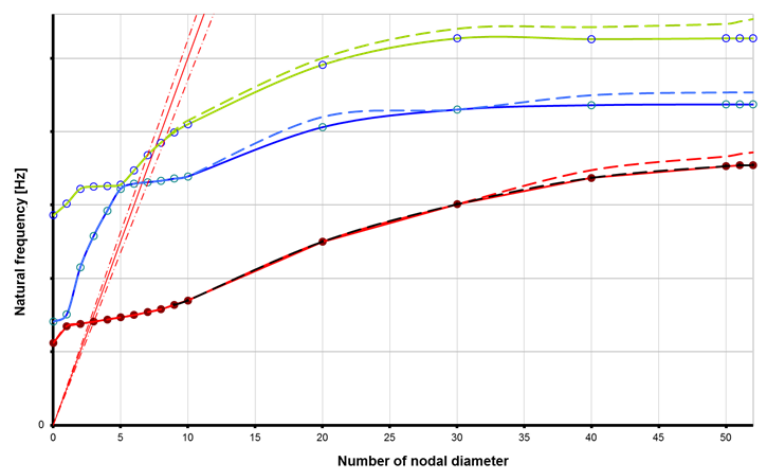

Fig. 9. Related frequencies comparison of max and min model. All frequencies related to the first mode frequency form $00 \mathrm{EM}$ test certificate.

Table 1. Formatting sections, subsections and subsubsections

\begin{tabular}{|l|l|l|l|}
\hline $\begin{array}{l}\text { Mode } \\
\text { No }\end{array}$ & $\begin{array}{l}\text { model min } \\
{[\%]}\end{array}$ & $\begin{array}{l}\text { model } \\
\max [\%]\end{array}$ & $\begin{array}{l}\text { Difference } \\
\text { \% }\end{array}$ \\
\hline 1 & 100,53 & 105,67 & 5,11 \\
\hline 2 & 193,67 & 194,93 & 0,65 \\
\hline 3 & 493,2 & 480,13 & 2,66 \\
\hline 4 & 741,27 & 742,17 & 0,12 \\
\hline 5 & 801,1 & 869,1 & 8,49 \\
\hline
\end{tabular}

The Campbell chart was a final verification of LSB dynamic analyses. As it can be seen in the Figure 10, the first mode is in proximity to the forbidden zone as per GE Power rules. An additional stress and strain analysis were made for these conditions to verify additional requirements applicable for this kind of cases (Figure 10). In a summary, there are no concerns regarding good dynamic behaviour of the reverse engineered LSB.

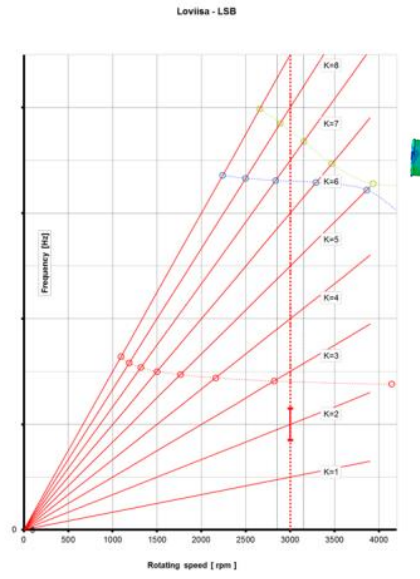

Max modal stress around protection zone

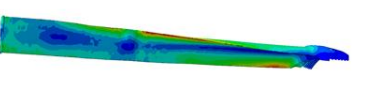

No node or deflection

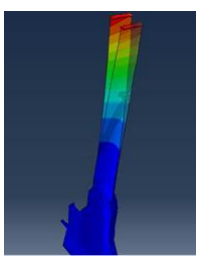

\subsection{LSB fatigue analysis summary}

A fatigue analysis was performed to reversed engineered design. As in other design criteria, fatigue analysis didn't rise any concerns. The critical location was identified in vicinity of damping wire. Lifetime consumption in this location is twice higher in comparison to average LSB lifetime consumption but yet below permissible limit.

\subsection{Summary of stress analysis}

It can be concluded that all internal GE design rules are fulfilled for reverse engineered LSB for Loviisa power plant. Moreover, all contractual requirements related to the appropriate level of similarity to oOEM design are also met. It was demonstrated that residual deviations from oOEM design for maximum and minimum models don't affect the dynamics of the blade row as a whole.

It is also wort to empesize usage of cutting edge nanoHVOF (High Velocity Oxygen Fuel) technology method to protect LSB against erosion. It was a pilot application of this method [5].

\section{Conclusion}

The reverse engineering process on an example of LSB for Loviisa power plant was presented in this article. The article describes also GE Power competences and capabilities to deliver spare parts for oOEM turbine. Described process can be used to deliver any component of a steam turbine, based on a physical element. As it was described all related risk to the reverse engineering process can me mitigate to meet even nuclear safety standard.

\section{References}

1. Shvetsova V. L., Kozheshkurta I. I., Koneva V. A., Boikob A. V., Usatyib A. P., Solodovc V. G., and Khandrimailov A. A., Improving the HighPressure Cylinder of the K220442M Turbine at the Loviisa Nuclear Power Station Thermal Engineering, Vol. 60, No. 2, pp. 98-105. (2013)

2. Murzynowski W., Grzesiczek E.: Wpływ geometrii i modeli obliczeniowych MES na rezultaty analizy stanu naprężeń w obrzeżach tarcz wirnikowych, VIII Sympozjum Informacyjno-Szkoleniowe, (2006)

3. Lipka J., Wytrzymałość Maszyn Wirnikowych, Wydawnictwa Naukowo-Techniczne, Warszawa (1967).

4. Rządkowski R., Sokołowski J.: Drgania własne ułopatkowanych tarcz wirnikowych osadzonych na wale, Akademia Marynarki Wojennej (2005)

5. Rehmus-Forc A., Topolski J., Matuszak J., Kucharski W., Ochrona antyerozyjna a konstrukcja na przykładzie inżynierii odwrotnej łopatki ostatniego stopnia części NP. turbin parowych, Energetyka, Vol. 27, pp. 36-38, (2016)

Fig. 10. Campbell diagram and point of concern analysis. 